\title{
The Chinese ba as a Verb: A Constructional-Cognitive Approach
}

\author{
Ronald Fong \\ Department of English, University of Macau, Macau, China \\ Email: ronaldf@umac.mo
}

Received 6 January 2015; accepted 9 February 2015; published 11 February 2015

Copyright (C) 2015 by authors and Scientific Research Publishing Inc.

This work is licensed under the Creative Commons Attribution International License (CC BY). http://creativecommons.org/licenses/by/4.0/

\section{(c) (i) Open Access}

\begin{abstract}
Although there have been various studies on the Chinese ba-construction, this article presents some unconventional views. Most studies do not treat $b a$ as a verb. This article argues that $b a$ is a verb, although it has some non-typical verbal properties. Firstly, the argument establishes that it is a verb based upon the "gradient" analysis, which has not been applied to ba before. Secondly, having been treated as a verb, ba shows special properties of its own such as marking subordination. Apart from this non-traditional view, ba is shown to be highly transitive, which is also a verbal feature. Different from previous analyses, this article argues that ba is a radial category showing various associated meanings. Finally, ba is shown to produce blending with other verb complements, such as the resultative construction, through its ability to create mental spaces.
\end{abstract}

\section{Keywords}

ba, Gradience, Subordination, Radial Category, Mental Space

\section{The Status of $b a$}

Among the widely discussed grammatical constructions in Mandarin Chinese is the ba-construction, exemplified in (1).

(1) John ba Mary da-si le.

John ba Mary hit-die asp (=aspect)

John hit Mary to death.

The ba-construction has been widely studied and is given various names. It is called the "disposal” construction by e.g. Wang (1954) or Chao (1968). Some regard it as an "ergative” construction (e.g. Frei 1956, Halliday 2001, Li and Yip 1979). Hashimoto (1971) calls it the "executive” construction, while Teng (1977) analyses it as an "accusative" construction. Other linguists simply consider it to be the ba-construction, for example 
Cheung (1973), Ding (2007), Huang et al. (2009), Li and Thompson (1981), Mangione (1982), Thompson (1973), Wang (1947/1959) and Sybesma (1992).

In this article we will discuss the general characteristics of the ba-construction and argue that: 1 ) it is a verb; 2) it signals subordination; 3) it has a dual-event structure; 4) there are extensions of senses of the construction and 4) it involves grammatical blending. The ba-construction, though extensively studied by linguists, is still as interesting as ever, partly because it apparently differs from the canonical SVO word order of Chinese, and partly because the $b a$-construction presents challenge to different theoretical frameworks. In the present study, we will make use of the constructional-cognitive insights, wherever appropriate.

\subsection{Diagnostics}

Perhaps the place to start our discussion of the $b a$-construction is to investigate the nature or status of $b a$. What is it? There are different ways in which we can define $b a$. First, we can examine its distribution to see what kind of positions it takes in a clause; or we can consider its functions in the language. The latter approach deals with the question why there is such a construction in Chinese but not in many more languages.

Huang et al. (2009: p. 165) conveniently summarise the previous analyses of the categorical status of $b a$ as, for example, a preposition (e.g. Chao, 1968; Li 1985, 1990) or a case assigner (e.g. Huang 1982; Goodall, 1987). Analyses that consider $b a$ as a verb are rare, exceptions include Hashimoto (1971) and the present study, in which we will argue that $b a$ is a legitimate verb or complement-taking predicate in Chinese, although it lacks some of the common verbal properties shown in many other verbs.

There are some standard tests for verbhood in Chinese such as the occurrence with an aspectual marker like le or guo to show the perfective meaning:

(2) Wo chi-le.

I eat-asp

I have eaten.

(3) *Wo ba-le fan chi le.

I ba-asp rice eat asp

I have eaten rice.

It is true that $b a$ cannot take an aspectual marker such as $l e$, while many other verbs in general can. However, $b a$ is certainly not the only verb that behaves as such. While the verb ai "love" can occur with guo "cross", it cannot take le.

(4) John ai-guo Mary.

John love-asp Mary

John has loved Mary.

(5) *John ai-le Mary.

John love-asp Mary

John has loved Mary.

Since Chinese verbs do not inflect for tenses, we cannot depend on this feature to distinguish between verbs and adjectives, for instance.

(6) Wo zuotian/mingtian chi huoguo.

I yesterday/tomorrow eat hotpot

I had hotpot yesterday.

I will have hotpot tomorrow.

Yet, many linguists (e.g. Huang et al. 2009, Li and Thompson 1981, Liu et al. 1996) will take example (3) as evidence that $b a$ is not a verb because it cannot occur with the aspectual marker $l e$.

However, I believe that is not the whole picture, and the model of gradience (Quirk et al. 1985, Aarts, 2007) seems to do ba more justice. According to Quirk et al. (1985: 90):

A gradient is a scale which relates two categories of description (for example two word classes) in terms of degrees of similarity and contrast. At the ends of the scale are items which belong clearly to one category or to another; intermediate positions on the scale are taken by "in-between" cases-items which fail, in different degrees, to satisfy the criteria for one or the other category.

They give the example of coordinating and subordinating conjunctions: 


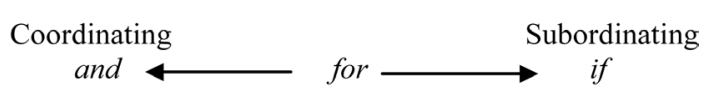

The item and is a proper coordinating conjunction and if a proper subordinating conjunction, as in John kissed Mary and she kissed him back, and I wonder if you like this shirt. However, the status of the item for as either coordinating or subordinating is difficult to establish, as in I don't want them, for they are expensive.

With this idea in mind, we can extend it to other categories. For example, verbs are said to exhibit a continuum of verbhood, in which some verbs are more verb-like than others, ie possessing more verbal properties.

A more recent study on gradience (Aarts 2007) provides us with a more detailed and scientific method of categorising words for their grammatical status. We may be able to solve the problem of categorisation of the Chinese $b a$ by applying what Aarts calls the "Subsective Gradience" model, which "is the phenomenon whereby a particular set of elements displays a categorical shading in propotypicality from a central core to a more peripheral boundary" (2007: 97). Following Aarts, I will argue that the Chinese ba exhibits Subsective Gradience in that it belongs to the class of verbs, but is not a core member of the class.

As has been shown, $b a$ does not license the suffixes $l e$ and guo, and thus for many Chinese scholars, it is not a verb. However, apart from verbal suffixes, there are other diagnostics available, such as the ability to take a complement, the possibility of being modified by adjuncts and by "not". If we take a prototypical verb chi "eat" and compare it with $b a$, we will obtain the following findings.

(7)

(i) Verbal suffixes

(ii) Taking complement

(iii) Being a verb complement

(iv) Standing alone

(v) Being modified by adjuncts

(vi) Being modified by meiyou "not"

(vii) Being in a predicator position

(following the first argument)

(viii) Occurring in A-not-A questions

(8) (i) a. Wo chi-le fan.

b. *wo ba-le fan.

(ii) a. Wo chi-le fan.

b. Wo ba chi-fan de shi wang le.

I ba eat-rice de matter forget asp

I forgot about the eating-rice business.

(iii) a. Wo xiang chi fan.

I want eat rice

I want to eat rice.

b. Wo xiang ba fan chi-le.

(iv) a. Chi!

b. *Ba!

(v) a. Wo kuaikuaide chi-wan fan.

I quickly eat-finish rice

I finished eating rice quickly.

b. Wo kuaikuaide ba fan chi-wan-le.

(vi) a. Wo meiyou chi-wan fan.

b. Wo meiyou ba fan chi-wan.

(vii) a. Wo chi-le fan.

b. Wo ba fan chi-wan-le.

(viii) a. Ni chi bu chi fan?

You eat not eat rice

Do you (want to) eat rice?

b. Ni ba $b u$ ba ta dang pengyou?

you ba not ba him regard friend 
Do you consider him as a friend?

In the above eight diagnostics or behaviour constructions (cf Croft, 2012: p. 20), chi has eight while ba possesses six-more than half, which makes me believe that $b a$ is a verb lacking some of the verbal properties. The last piece of evidence (7 and 8 viii) suggests that there is a close connection between $b a$ and auxiliary verbs. Perhaps $b a$ is moving towards to the auxiliary group and will become fully grammaticalised. All in all, the conclusion we should draw here is that $b a$ is a verb; its position can be located along a continuum: chi $b a$ shu 'book'
$\longrightarrow$ Non-verb

Although chi and $b a$ do not occupy the same position on the continuum, $b a$ is certainly more verb-like than shu "book".

Nevertheless, one may object to the seemingly equal weight given to all the properties above. For example, taking a verbal suffix seems to be more important than being a complement for a verb. Perhaps we could assign some values to the properties, for instance, $0-1-2$. Taking a verbal suffix is assigned the value of 2 , and taking a complement the value of 1 . There are two properties ( $7 \mathrm{i}$ and $7 \mathrm{iv}$ ) that we could assign 2 , respectively and other properties are assigned 1 . Thus, the scores for the negative properties are 4 and those for the positive ones are 6. One may also object to how we decide on the values. With all these objections, however, it is important to note that the number of verbal properties of $b a$ cannot be ignored.

Surprisingly, we also find this kind of gradience phenomenon in English. A classic example will include the distinction between auxiliaries and verbs. Do we have a single class of verbs or two distinct classes of verbs (Aarts 2007)? Or do we recognise a class "semi-auxiliaries", which show behaviours of both a verb and an auxiliary? Another interesting case will be the English gerund such as eating. Is it more like a verb or a noun? Yet, another example in English, which behaves like $b a$, is the verb beware, which does not take the present and preterite inflections, as in *John bewared of the dog last night. We treat beware as a verb for other verbal properties it has. Thus, we suggest that $b a$ is a verb in Chinese because it has certain verbal properties and lacks some others.

\subsection{Meaning and Category}

Another more general reason why we classify $b a$ as a verb is that we do not want to establish a particular category, whose members contain only ba, such as "co-verb" or "case-assigner". These are ad hoc terms and specific to Chinese, and so weaken the typological significance of terms like "verb" and "noun", whose validity is shown in many languages. Further, "case-assigner" is not a traditional word class or syntactic category and it can cover prepositions and verbs.

For those who prefer a semantic or notional analysis of categories to a distributional one, there is also evidence that $b a$ is a verb. Even if $b a$ is taken to be rather empty in terms of its lexical content, it can still be considereda verb. If we take into account the light verbs in English such as have and take, we will find that in one use, they do not have lexical content but perhaps "schematic" meaning-a more abstract and general meaning based on the verbal construction. A schema, according to Langacker (1990: p. 59) is "an abstract template representing the commonality of the structures it categorises, which thus elaborate or instantiate it”. Examples (9 and 10) instantiate the [HAD NP] and [TAKE NP] constructions, respectively. Their "meaning" has to depend upon the following complement.

(9) John had an argument with Mary.

(10) John took a shower.

(9) means that John argued with Mary, and take in (10) has to do with showering. There is no reason why we should not consider them verbs; also, there is independent evidence that they are verbs, namely tense inflection. Another example is the auxiliary verb in John was laughing, where was ...ing gives the progressive interpretation, but was does not have lexical content in itself. Yet, it is commonly accepted as a verb. As a consequence, lack of lexical content is not sufficient evidence for rejecting a word as being included in a particular category.

Following Hashimoto (1971), Ding (2007) also takes $b a$ as a verb but the present study presents different kind of evidence and further argues and explicatesits consequences, from formal and functional evidence. One argument is that the $b a$-complement shows subordination. As a result, the entire $b a$-sentence will be, in tradition terms, "a complex sentence". However, following Huddleston and Pullum et al. (2002), the present analysis abandons the clear distinction between a simple sentence and a complex sentence as adopted in traditional gram- 
mar of Chinese (e.g. Tsao 1980)—we instead recognise the concept of clausal sentences, which subsumes the traditional distinction. This concept is in line with one of the major properties of language, ierecursion, in that there are as many subordinate clauses as required. More importantly, I believe that without this traditional distinction, we can examine the clause structure in Chinese more effectively.

\section{Subordination Marking}

Having argued that the Chinese $b a$ is a verb, we will consider complementation of $b a$ now. In the literature, most studies are concerned with the NP immediately following $b a$, and thus is often characterised as the following structure (Tsao 1990: p. 169):

NP $b a$ NP V NP or Subject $b a$ Object Verb Complement

The post-ba NP is said to be definite in that the speaker and hearer are assumed to know what it refers to.

(11) Ta ba huaping da-po le.

he ba vase hit-break asp

He broke the vase.

In this example, huaping is known to the speaker and hearer, and in some earlier transformational models, it is moved from the underlying object position of $d a$ to the post-ba position. In our present study, we do not assume such kind of operation as we take the "what-we-see-is-what-we-get" approach (Goldberg, 2006). There is also a further problem in the traditional model. The traditional object comes before the verb inside the $b a$-complement, which violates the canonical word order in Chinese.

\subsection{Binary Branching}

It seems preferable in our investigation to cpnsider the $b a$-construction as it is, without syntactic derivation. Instead of singling out the post- $b a \mathrm{NP}$, I would suggest that we regard the entire post- $b a$ item as a constituent binary branching, and thus having the following structure:

(12) X [ba [Y Z]]

Ta [ba [huaping da-po le]].

$\mathrm{Y}$ and $\mathrm{Z}$ are supposed to be a single unit in this model, although a flat structure model may be assumed (cf Culicover and Jackedoff, 2005):

(13) X [ba Y Z]

Ta [ba huaping da-po le].

If the above analysis of $b a$ as a verb (Section 1.1) is viable, the treatment of the post-ba element as a subordinate clause is not entirely impossible. First, if we examine the internal structure of the post-ba element, we will find predicate argument structure (cf Grimshaw, 1990 for different formal representations):

(14) $d a$ (ta, huaping) po (huaping)

While the external argument $t a$ is not our concern here because it is outside $b a$, we still find $d a$ and po predicating of the argument huaping. This is no accident, as the ba-construction has its own preferred argument structure (cf du Bois, 2003). The subordinate structure exhibits some kind of "ergativity" or "unaccusativity" (Perlmutter 1978, Burzio 1986) in that the "underlying object" is realised as the "surface subject". The unaccusative hypothesis is argued to be semantically determined, and syntactically represented (Levin and Rappaport Hovav 1995). In (13) and (14) huaping "vase" is the Patient argument of da "hit" and the Theme/Patient argument of po "break". The following examples show how they behave when used individually:

(15) Ta da-le huaping.

he hit-asp vase

He broke the vase.

(16) Huaping po-le. vase break-asp

The vase broke.

In (15) the vase is the "object" and "subject" in (16). The ba-construction can be used to express these two ideas, with the merging of the verbs in the internal resultative construction-Ta ba huaping da-po-le. Thus, the $b a$-complement structurally presents unaccusativity, making the post- $b a$ argument more salient and producing the final result: the vase broke. The result is dependent upon, to some extent, the kind of verbs that occur in the 
ba-complement.

However, not all verbs or classes of verbs can occur in the ba-complement, for instance:

(17) *John ba Mary hen-le.

John ba Mary hate-asp

John hates Mary.

This example is unacceptable and has to do with the semantic class of the verb hen "hate". In general, a stative verb cannot occur in the $b a$-construction as it does not bring about anything or make anything happen. However, with modification, this example will become acceptable:

(18) John ba Mary hen-si-le. John ba Mary hate-die-asp

John hates Mary so much that he could die.

The resultative is compatible with the conceptual structure of the ba-construction showing manipulation, result or change of state. Leaving aside the internal structure of the resultative inside the ba-construction, we could postulate a dual-event structure, initiated by ba.

(19)

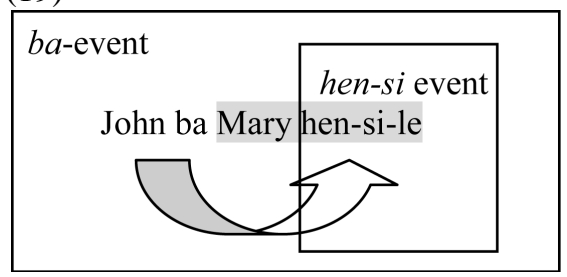

\subsection{Motivation and Events}

The plausibility of this analysis comes from the cognitive-functional definition of subordination. According to Cristofaro (2003: p. 2), subordination can be seen as:

a particular way to construe the cognitive relation between two events, such that one of them (which will be called the dependent event) lacks an autonomous profile, and is construed in the perspective of the other event (which will be called the main event).

Although this is not immediately obvious, this way of viewing subordination can capture the relation between $b a$ and its complement in the construction. I argue (2012) that the resultative construction is merged by two sub-events and if all the details are needed in the following diagram, hen-si would constitute another dual-event structure. For the present purposes, let us consider the ba-construction containing two events. The term "event" in this study has a broad sense meaning roughly "state of affairs” (Cristofaro, 2003) or "situation”.

One may wonder why ba constitutes an event as it does not seem to have full lexical content in itself. That is a legitimate question and demands an answer if we want our theory to work. At this point, we could rely on a temporal interpretation of event such as that proposed by Goldberg (1998: 42):

Two events e1 and e 2 are distinct subevents of an event $\mathrm{E}$ designated by a verb $\mathrm{V}$, iff $\mathrm{E} \rightarrow \mathrm{e} 1 \&$ e2 is not completely within the temporal extent of e2.

Goldberg (1988: 42) gives the example of saute, which designates one event 'since the two aspects of heating and stirring overlap temporally such that the stirring is completely within the temporal duration of the heating'. Now consider the temporal constraints on $b a$ and those on the event inside the ba-construction. There is no temporal distance between $b a$ and say hen-si in the above case. Structurally, one cannot stop at ba such as *John $b a$; and cognitively, ba and (Mary) hen-si constitute a tight relation as if they actually "happened" simultaneously. We cannot even insert an adjunct between ba and Mary hen-si le, such as *John ba feichangde Mary hen-si le ("John hates Mary so much").

Furthermore, the ba-event carries modality. Similar to a clause, the ba-construction adds modality to the proposition expressed by the ba complement clause as some kind of actuality (Palmer 1990). While the canonical resultative construction can allow the potential form with $b u$ "not", the ba-construction typically does not allow that. Thus, $b a$ is not used to present non-actuality.

(20) John da-bu-si ta. 
John hit-not-die him

John hit him but cannot kill him.

(21) John ba ta da-si-le.

John ba him hit-die-asp

John killed him (by hitting him).

(22) *?John ba ta da-bu-si.

It is the conceptual meaning of $b a$ such as manipulation or result (actuality) that disallows the potential form to occur inside the $b a$ complement, as $b a$ implies a result or some kind of manipulation.

As we already argued in (9 and 10), lack of lexical content does not bar a word from being included in a particular category. Nor does it prevent a verb from denoting an event. If we consider the light verbs in English again, we will agree that have an argument with Mary constitutes an event, although the meaning of have relies on its complement. For we cannot have *We an argument with Mary without have. A further piece of evidence comes from the English participial clause such as the following:

(23) John had [his hair [cut nicely]].

(24) John ba [toufa [gei jian-hao-le]].

John ba hair give cut-good-asp

John had his hair cut.

Following Huddleston and Pullum et al. (2002) and Quirk et al. (1985), we take cutnicely as a participial clause, subcategorised for by had. Similarly, ba in the next example subcategorises for toufa gei jian-hao-le. This shows that again, the $b a$-complement is subordination.

Implicit in this analysis is the claim that $b a$ is similar to a "catenative" verb, taking a complement clause containing a resultative construction. Thus, $b a$ is like the verb persuade in English taking an NP argument and a clausal complement, although the latter has full lexical content.

(25) John persuaded Peter to kill Mary.

(26) John ba Mary da-si-le.

John ba Mary hit-die-asp

John killed Mary by hitting her.

The $b a$-structure is then an embedding structure having the resultative as subordination. This is also found in English such as John intended Mary to expect to find a better husband. The fact that after ba no aspectual marker can occur acts against it as cosubordination.

(27) *John ba-le Mary da-si-le.

Thus, on the continuum of the complex sentence types (Croft 2001), the ba-construction leans towards the complement end of the continuum, between adverbial clauses and complement clauses. Reinforcing the conclusion of the last section, this catenative analysis, in my view, should provide an effective model for Chinese grammar.

\subsection{Typological Relevance}

Typologically, there is further evidence that the $b a$-construction shows subordination: it contains a subordinate complement clause. Dixon (2010: p. 129) defines a complement clause by the following three main criteria:

(i) It has the internal structure of a clause, at least as far as core arguments are concerned. Whether peripheral arguments may be included—and if so, which ones—varies from language to language.

(ii) A complement clause functions as a core argument of another clause. If a complement clause is in $\mathrm{O}$ function, for instance, it should show at least some of the syntactic properties of $\mathrm{O}$ in that language.

(iii) A complement clause will always describe a proposition; this can be a fact, an activity, or a state (a place or time).

The $b a$-complement contains the internal argument (i), and it has the $\mathrm{O}$ function after $b a$, where $b a$ is the subordinating boundary (ii) and it shows a proposition (i.e. event) (iii), as we have seen in how modality and proposition are blended in the structure.

Moreover, the $b a$-construction manifests the typological type of manipulative meaning as that argued for by Cristofaro (2003), which is high on the subordinate clause deranking hierarchy.

The Hierarchy of Subordinate Clause Deranking

modal, phasal $<$ purpose $<$ manipulative, desiderative $<$ perception $<$ before $<$ after, when $<$ reason, reality 
conditional $<$ knowledge, propositional attitude $<$ utterance

This scale measures the degree of semantic integration, which shows connections between two states of affairs. Two states of affairs are seen as one event through the use of modals and phasals, while manipulatives and desideratives can denote events that are dependent upon another (Croft 2002: 218). The ba-construction can be understood as a structure manipulating others. Furthermore, the hierarchy shows more support to the idea that the $b a$-construction must take a complement (clause), and that $b a$ also expresses a kind of purpose and result. Thus, $b a$ should occur between "purpose" and "manipulative" on the scale. They are close together because they denote similar concepts, and another way to interpret the ba-construction is to see it as a "double-resultative" structure, whose resultative function is taken to be primary in this study, with example (26), repeated here as (28).

(28) John ba Mary da-si le.

$$
\begin{aligned}
& \text { ba-resultative } \\
& \text { resultative }
\end{aligned}
$$

If the canonical resultative emphasises the outcome of the event, the $b a$-construction emphasises both the patient argument (sometimes regarded as a secondary topic by linguists such as Tsao 1990, Xu and Liu 2007) and the outcome of the resultative event, by making the patient argument close to $b a$, so that the hearer or addressee must wait until the end to find out such new information as the activity and outcome of the event.

If all these arguments are valid, we will have argued that $b a$ constitutes an event with its complement contributing to another event. Simultaneously, ba signals strong subordination (also via deranking), which does not seem to be widely accepted for the moment. Moreover, functionally, the $b a$-complement shows manipulation, result and actuality.

\section{Transitivity}

\subsection{Syntax and Semantics}

Having examined the evidence that $b a$ is a verb and marks subordination, we can easily see that $b a$ is a highly transitive item, both syntactically and semantically (following Hopper and Thompson 1980). According to Tsunoda (1994), we should distinguish between the semantic and morphosyntactic features of transitivity. Furthermore, transitivity is a matter of degree or a continuum/scale (Hopper and Thompson 1980). In other words, the more transitivity features a clause has, the more transitive a clause is. A clause with more transitivity features will be more transitive than a clause with fewer features. They (Hopper and Thompson 1980: p. 255) propose the transitivity hypothesis, which states:

If two clauses [a] and [b] in a language differ in that [a] is higher in Transitivity according to any of the features 1A-J, then, if a concomitant grammatical or semantic difference appears elsewhere in the clause, that difference will also show [a] to be higher in Transitivity.

Ten other semantic parameters are proposed to be subsumed by transitivity, particularly, the prototypical transitive clauses. They are participants, kinesis, aspect, punctuality, volitionality, affirmation, mode, agency, affectedness of $O($ bject $)$ and individuation of $O($ bject). The prototypical transitive verbs can be defined as those involving an activity that causes a change in the patient. Together with these ten parameters, a sentence is said to exhibit a continuum of transitivity. In other words, some sentences have a high degree of transitivity and others low.

Apart from the semantic properties, prototypical transitive clauses are also characterised by possessing the morphosyntactic properties such as linguistic expressions of the two participants, namely, agent and patient; case frame; verbal morphology; and the possibility of parallel constructions like passive and antipassive, reflexives and reciprocals, and so on. These properties are also used traditionally to distinguish between transitive clauses and intransitive clauses.

\subsection{The Case of $b a$}

As Chinese does not have rich verbal morphology, the syntactic parameters are not as useful as the semantic ones. The verb $b a$ takes two arguments-the external argument, usually having agency and volitionality and the internal argument, realised by the $b a$-subordination, usually having affectedness, for example, (26). Thus, the prototypical ba-construction such as John ba Mary da-si-le ("John killed Mary by hitting her") is highly transi- 
tive, having Mary da-si-le as its complement. Relevant to our discussion here is the semantic aspect of change and impingement (Tsunoda 1994: p. 4675), which link the ba-construction to the transitivity hypothesis closely. Thus, the sentence John ba Mary da-si-le "John killed Mary by hitting her" is fine, but John ba Mary xihuan-le is bad. The resultative da-si shows a change of state, impingement on the patient, and there are the participants "killer" and "killee". If we can organise the different kinds of resultative constructions along such a continuum, it may look like this:

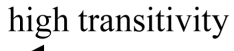

English:

John killed Mary. John shouted himself hoarse. John cried so that the pillow got wet.

For the English resultative, a high transitivity seems to be the nature of the resultative construction, hence the requirement of Direct Object Restriction, while the Chinese ba-construction is high on the scale. Since the $b a$-construction is highly transitive, it can naturally express concepts such as manipulation, results and actuality of events.

The question to ask now is: is there a $b a$-construction that shows less transitivity? In terms of syntax, we have already seen that the $b a$-construction must take a complement and is thus transitive; but semantically, there are $b a$-complements having lesser degrees of affectedness. Mei (1978, also cited in Tsao, 1990: p. 198-199) gives the following and argues that $b a$ here does not seem to have the typical interpretation such as manipulation and handling:

(30) Ta ba yi-ge da hao jihui cuoguo le.

he ba one-CL very good opportunity miss asp

He missed a very good opportunity.

It is indeed not easy to consider an opportunity to be manipulated or handled but it is still transitive in that it demonstrates the semantic features such as punctuality and aspect (Hopper and Thompson 1980). The verb cuoguo "miss" suggests a perfective aspect, as guo "cross" implies that something has passed; and aspect is high on the transitivity hypothesis. Zou (1993) also investigates the $b a$-construction, and finds an objective type:

(31) John ba pingguo bo-le pi

John ba apple peel-asp skin

John peeled the skin of an apple.

We can also have John ba pinguo de pi bo-le, and very clearly we see a strong degree of affectedness here the apple has no skin now. All we have said about the $b a$-construction is that it conveys certain transitivity features and it only makes sense if we have the $b a$-complement as a case of subordination and an event. Thus, transitivity demonstrates the phenomenon of gradience, which lurks behind the grammar of Chinese and helps us with the categorisation of $b a$ and its complement. Crosslinguistically, the $b a$-construction shows, as Goldberg observes (1995: p. 118), that "Languages differ in how and to what extent the transitive construction is extended to express nonprototypical semantically transitive scenes".

\section{Meaning and Blending}

\subsection{Meanings of $b a$}

Among the various senses that the $b a$-construction can express, the one of "disposal" stands out and it is often called the "disposal” form, which also demonstrates a strong sense of transitivity. Consider L Wang's (1947: p. 160-161) original formulation:

The disposal form states how a person is handled, manipulated, or dealt with, how something is disposed of, how an affair is conducted. Since it is specifically designed for disposing, the disposal form cannot be used unless the action possesses the quality of disposal.

(translated by Y-C Li 1974: p. 95)

That the term disposal is widely used, although many linguists, for example, Lü (1948), H Wang (1959), and Chao (1968), have pointed out the inadequacy of Wang's original theory of disposal before the idea of affectedness was introduced (e.g. Tenny, 1987). In fact, more recent studies like Q Wang (1985) understand the concept 
as basically the same as that of affectedness but just use the traditional term "disposal”. We maintain that disposal is a useful concept, and that the disposal type is the prototypical ba-construction.

In a nutshell, the literature against the meaning of disposal as the defining property of the ba-construction includes the following reasons:

(i) The verbs in some of the $b a$-sentences which express emotion, thought, or perception, have no disposal meanings, for example, John ba Mary hen-si-le ("John hates Mary to the extreme").

(ii) In some $b a$-sentences, the element introduced by $b a$ does not represent the patient of the action, but other semantic roles, for instance, John ba huayun zhong-man-le hua ("John planted the garden full of flowers"), where huayun "garden" is a location.

Seemingly, the disposal approach is defective. However, despite this criticism, the idea of disposal is still widely adopted among Chinese linguists. As Song (1991) points out, what is noteworthy of the disposal idea depends upon how one interprets the term. For somelinguists, for example, Liu et al. (1996: p. 415), "disposal” expresses how one intentionally disposes of something. According to this literal interpretation, many $b a-=$ sentences cannot be accounted for. If we understand the term in a broader sense, as in Li and Thompson's (1981) metaphorical use of the term, the idea of disposal can be accepted more easily. They (1981: 483) take "disposal" to mean "something happening to the entity referred to by the ba noun phrase". Song (1991: p. 5) gives a revised version of the interpretation of "disposal":

The action represented by the predicate of a sentence has some positive effect on the element introduced by $b a$, making the element undergo some kind of change, produce some kind of result, or be in some kind of state.

Accordingly, "disposal” indicates the relationship between verbal structure and the element introduced by $b a$, but not the intentional behaviour of the agent or theme represented by the subject.

Traditionally, the advantages of recognising the disposal function or meaning of the ba-construction include pragmatic concerns. In the $b a$-counterpart of the following examples, the $b a$-construction is used for focus, emphasis and definiteness (e.g. Teng 1971, Thompson 1973, Li and Thompson 1981), and has a stronger tone than the non-ba sentence.

(32) Dai ta shang-lai

bring him up-come

orin a ba-construction:

(33) $\mathrm{Ba}$ ta dai shang-lai

ba him bringup-come

Bring him up.

Although it seems that the $b a$-construction can express several different kinds of meaning, bringing about a result appears to be more common than others. We can rely on Aarts's model of Subsective Gradience to arrange the various meanings and functions of the ba-construction, again, on a continuum. The meanings on the left fit the definition of disposal by $\mathrm{Li}$ and Thompson in that they all involve "something happening to the entity referred to by the $b a$ noun phrase".

(34)

$$
\begin{gathered}
\stackrel{\text { least prototypical }}{\text { prototypical }} \\
\text { disposal result change of state manipulation } \\
\{\text { 'Something happening.... }
\end{gathered}
$$

The major problem with many previous studies is to take "disposal" or any other meaning as one single overarching meaning or defining criterion of the $b a$-construction. Instead, we should recognise the various meanings that the $b a$-construction can express through its interaction with the complement.

\section{2. $b a$ and the Resultative}

While different from the resultative construction, the ba-construction takes the arguments of Agent/Actor/ Causer and Patient/Undergoer/Causee-these are proto-roles or macro-roles (Dowty 1991, Van Valin 1990). The Patient is realised by subordination that includes the Patient of the complement verb and the Result-Goal realised by a resultative construction. 


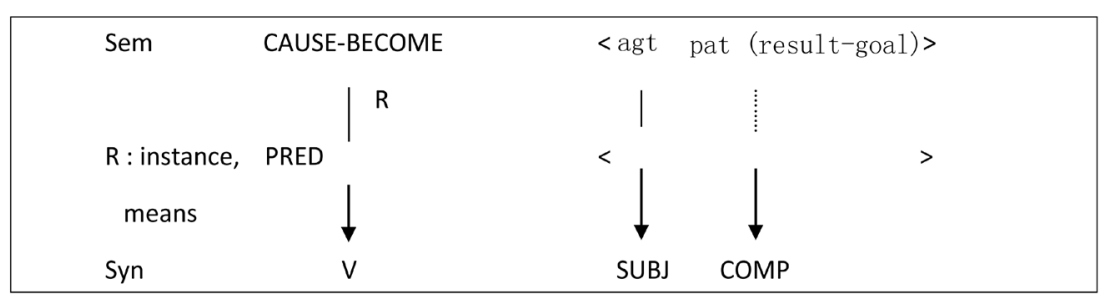

In the above diagram result-goal is simply used as a convenient label and should be taken metaphorically as change of state. Moreover, we recognize the causative nature of the construction. Instead of taking the resultative as an oblique, we consider it simply to be a complement subcategorised by $b a$. Thus, the $b a$-construction exists independently of other constructions, given its syntactic, semantic and pragmatic functions.

In the above case, the post-ba NP Mary must be adjacent to ba. This “adjacency requirement” is derived from the general iconicity principle that conceptually closely related items come close in the structure of language. A subtype of iconicity is isomorphism (Haiman, 1985) between meaning and form. In the ba-construction the meaning of the construction requires that the NP argument be next to it, since the argument is an Undergoer for some kind of change or for some effects. Furthermore, (29) also shows strong support to the iconicity principle that nothing can occur or interfere between $b a$ and its complement. The structure matches the meaning in the way things happen.

\section{3. $b a$ and Construction Grammar}

In this connection, it will be appropriate to adopt the polysemy links used in Construction Grammar (eg Goldberg, 1995). These links "capture the nature of the semantic relations between a particular sense of a construction and any extensions from this sense” (Goldberg 1995: p. 75). For instance, the caused-motion construction has several related senses (Goldberg 1995: p. 76), that is: 1) X causes Y to move Z; 2) conditions of satisfaction imply "X causes Y to move Z”; 3) X enables Y to move Z; 4) X causes Y not to move from Z and 5) X helps Y to move $Z$. The first one is a central sense and others are derived from it. Thus, one way of looking at the baconstruction is through this polysemy link with the caused-motion construction:

(36)

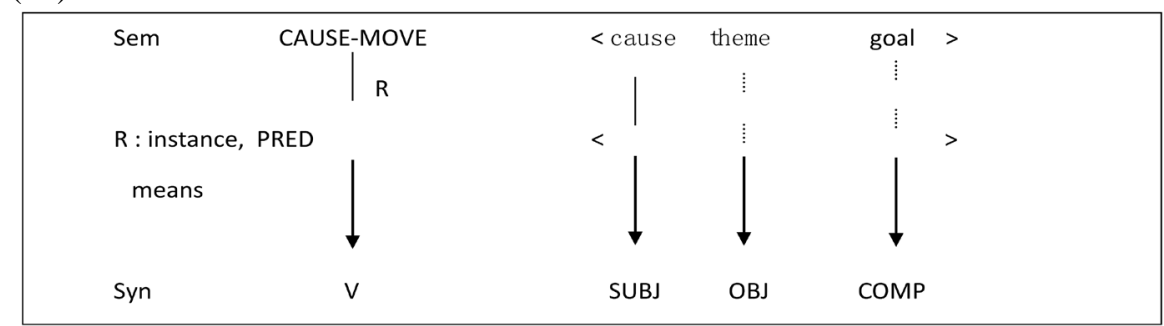

This is similar to the previous diagram but this one is explicitly about caused-motion. In (26) John ba Mary da-si-le, John puts Mary in a different state (death) as if he moved her to a different place. This is a metaphorical extension.

The following shows a variety of meaning denoted by the ba-construction through the interaction of the complement verbs:

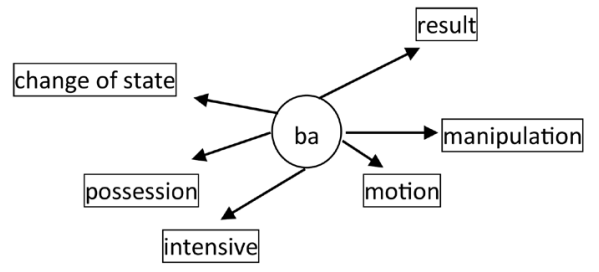

Some examples include:

(38) John ba yingyinben fang-dai-le. John ba photocopy open-big-asp

(change of state)

John enlarged the book.

(39) John ba pingguo bo-le pi John ba apple peel-asp skin

(possession) (=31) 
John peeled the skin of an apple.

(40) John ba shuben ban-dao waimian qu.

(movement)

John ba book move-arrive outside go

John moved the books to the outside of the building.

(41) John bu ba wo dang pengyou.

(intensive)

John not ba me as friend

John does not regard me as a friend.

(42) John ba fan chi-wan-le.

John ba rice eat-finish-asp

John finished eating his rice.

As a consequence, a better way to characterise the $b a$-construction in terms of meaning, in my view, is to consider them in a scale of gradience from the cental $b a$-construction meanings to the non-ba-construction meanings. Furthermore, in the construction grammar framework (e.g. Goldberg 1995), multiple inheritance is allowed so that the exact interpretation of the ba-construction depends upon the input from the predicate, the $b a$-construction and the construction associated with a particular meaning. If we take, again, (26) John ba Mary $d a-s i-l e$ as an example, the following diagram may represent how the sentence obtains its meaning. Instead of two inputs, $b a$ also contributes to a more abstract meaning associated with result, manipulation, movement, etc. In other words, $b a$ can be considered to be a radial category (Lakoff 1987) in the sense that it is defined by conventions but may not be predicted by rules. As a result, if the historical meaning of $b a$ as "take" or "hold" is regarded as the basic model, from which all other semantic models are derived, the following models will be produced:

(43) a. disposal

b. result

c. change of state

d. manipulation

e. possession

f. motion

g. intensive

This list is not exhaustive, and as has been said earlier, the interpretation of the ba-construction depends on its interaction with the complement. When the different conditions meet collectively, they may form a prototypical case of a category, which may instantiate the Idealised Cognitive Model (ICM, Lakoff 1987) of the category. In the case of $b a$, speakers may consider result or disposal to be central properties of the function of the $b a$-construction.

(44)

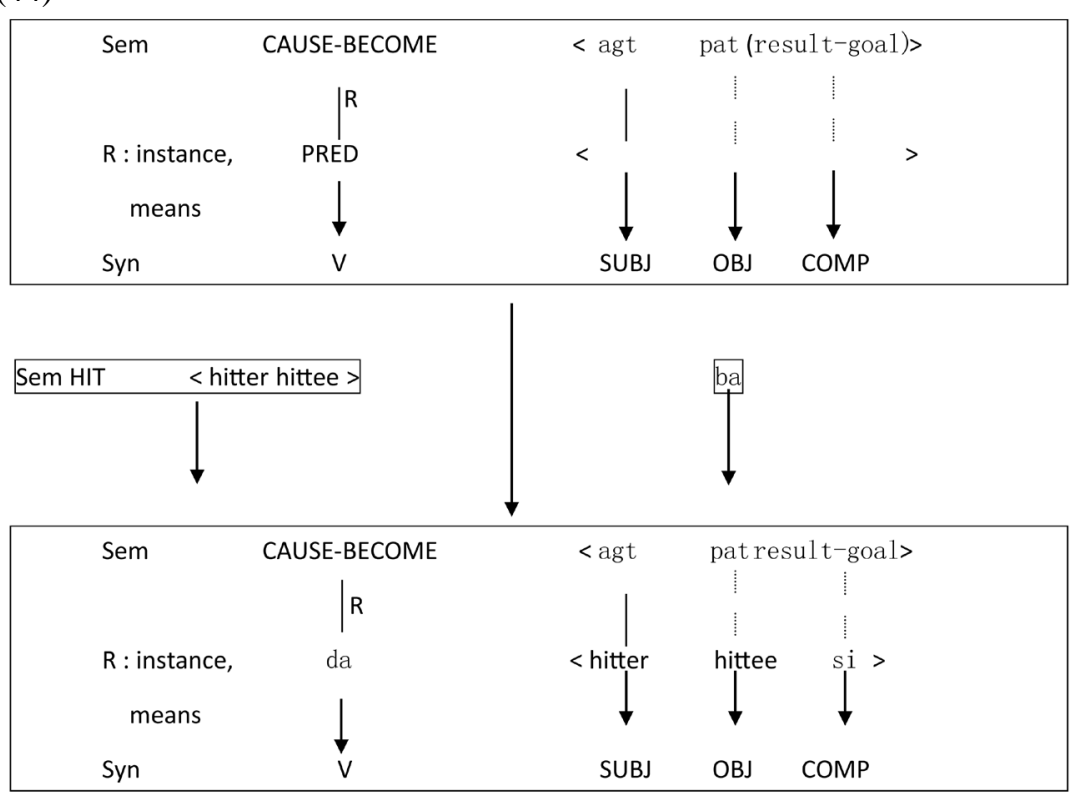


The above diagrams show how the ba-construction is fused from different structures and semantic areas. This metaphorical extension, in my view, involves transitivity in different senses. Under the transitivity hypothesis, John acts on Mary in example (26) above, which involves participants, change and impingement. In terms of structure, the postverbal NP argument must be present and that fits the traditional concept of transitivity. Another sense is that the relationship between the caused-motion construction and the ba-construction is transitive.

Similar to the caused-motion construction, the many senses of the ba-construction have to do with force-dynamics (Talmy 1985), or the causal chain of the event (Croft 1991), showing the transmission of force by the agent and the end of the transmission towards the patient. Following Croft (1991: p. 173, 1994), a simple event involves the causal chain indicating that 'the prototypical event type that fits this model is unmediated volitional causation that brings about a change in the entity acted on'. The following diagram shows the model:

(45)

\begin{tabular}{|c|c|c|c|}
\hline Initiator & endpoint & (endpoint) & (endpoint \\
\hline - $\quad \rightarrow$ & $\rightarrow$ & $(\bullet)$ & $(\bullet)$ \\
\hline CAUSE & CHANGE & STATE & \\
\hline
\end{tabular}

The prototypical ba-construction such as (26) John ba Mary da-si-le can be expressed in this model: John is the initiator (hitting Mary), Mary changes state and she becomes dead (result). This also corresponds to the unique path constraint (Goldberg 1995: p. 82) that, simply put, there is only one path for motion event or one result for each result event, as witnessed by the following example:

(46) *John ba Mary da-shang-si-le.

John ba Mary hit-injure-die-asp

John hit Mary and she was injured and dead.

(47) *John ba shuben yi-zuo-kai-le.

John ba book move-go-away-asp

John moved the books away.

Thus, the ba-construction observes the causal chain and unique path constraints, as it reflects the natural happenings of the world. What is special is that the construction has a non-canonical structure that reinforces the $b a$-construction status unique in Chinese grammar.

\section{4. $b a$ and Blending}

Being a construction, in the sense of Construction Grammar, the ba-construction, in this use, can be considered to be a kind of grammatical blending (Fauconnier 1994, 1997). Following construction grammarians such as Goldberg (1995), a metaphorical extension of the caused motion construction- "A causes B to move to C by doing D" can be extended to the ba-construction. The following schema is a version adopted from Fauconnier (1997: p. 173):

(48)

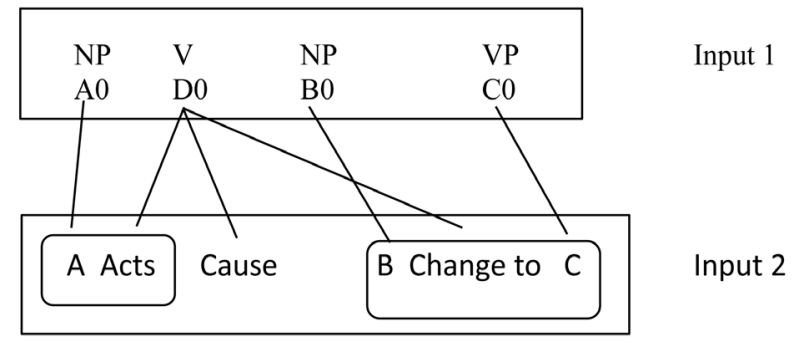

Here, we replace Fauconnier's "Move" to "Change to" to denote the change of state in the ba-resultative structure. Under this blending, there are two inputs—one for the structure and the other for the meaning. They have to match in order to produce the cause-result meaning of the $b a$-construction. In other words, $b a$ can be regarded as a space builder that anticipates the following event, as shown below:

(49) 


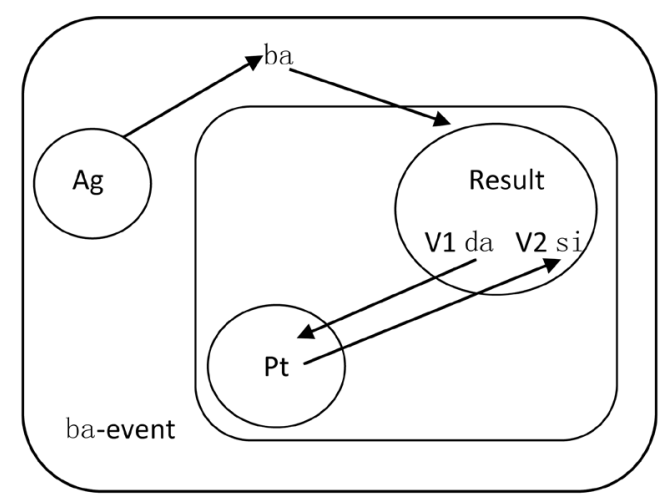

In this view, the main function of $b a$ is to present the stage for the following event to unfold in the discourse, in relation to the Agent. It does not only highlight the Patient but the entire event associated with the arguments. Since the word $b a$ itself does not have much lexical content, it interacts with its complement as a whole to achieve the construction's meaning such as manipulation and change of state. Thus, we know what kind of events is involved in John ba Mary da-si-le, but not *John ba. The exact meaning of ba is derived from the entire construction.

As a space builder, ba can contribute to various mental spaces (Fauconnier 1994, 1997), depending upon how it is actually used in the discourse. It creates different spaces matching the individual meaning of the complement. Although we recognise that perhaps the more central meaning of the $b a$-construction is "disposal" or "cause-result”, the less prototypical, unpredictable meaning provides further support to the idea that the $b a$-construction is a construction of its own, as shown in (31), repeated here.

(50) Ta ba yi-ge da hao jihui cuoguo le.

he ba one-CL very good opportunity miss part (CL = classifier)

He missed a very good opportunity.

The exact interpretation of the ba-construction depends on several factors. Structurally, there are the verbal elements, and the construction is transitive in nature. Semantically, the meaning of the verbal elements must be compatible with the meaning of the ba-construction, for example, producing results or change of state. In other words, the construction's argument structure roles must be fused with the corresponding participant roles provided by the verbal element (Goldberg 1995). There is, last but not least, context in which the construction is used.

On the other hand, the mental spaces that $b a$ builds provides us with a convenient way to understand the discourse and the relationship between the participants and the spaces.

(51)

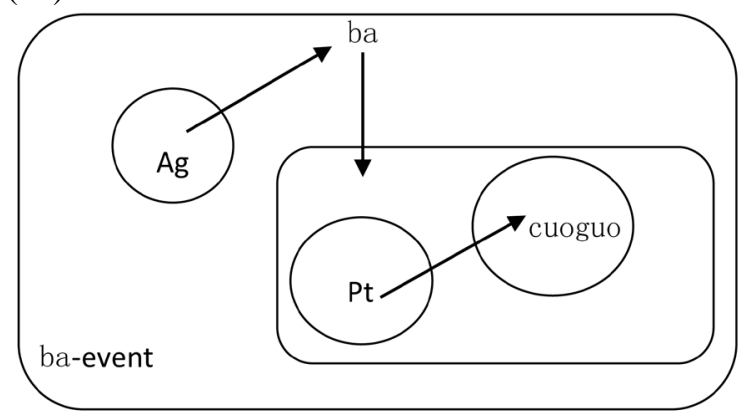

In this example cuoguo is more like a single unit as the bu "not" insertion is not allowed here: cf. *cuo bu guo "not miss", which perhaps constitutes a single event. So, on one interpretation the Agent may or may not have intentionally missed the opportunity, and the Patient or Theme here does not seem to undergo any transformation and change. The function of $b a$, again, is to establish a stage for the event to begin in the discourse. The diagram above is meant to illustrate the flexibility of the blending model to fit the various senses of the $b a$-construction.

Since the $b a$-construction often produces result and change of state, it is highly compatible with the canonical resultative construction. They are often inter-dependent. The examples of their co-occurrence abound: 
(52) John da-si-le Mary.

(53) John ba Mary da-si-le. (=26)

Structurally, although the resultative and the $b a$-construction have high transitivity, the ba-construction is a larger construction than the resultative construction and therefore the resultative construction is contained within it. (Incidentally, this analysis is compatible with a formal analysis proposed by Huang et al. 2009, where the entire sentence is treated as a $b a$-phrase). In (54) there is the resultative construction as we have already seen, whichthe $b a$-construction contains. Here we assume that the $b a$-construction also consists of the subject argument. Another way of looking at this is that $b a$ is considered to be the head of the entire clause, although there can be adjunct insertion between the subject argument and $b a$.

(54) John henhendeba Mary da-si-le.

The adjunct henhende "fiercely" shows the manner modifying ba Mary da-si-le, expressing a strong sense of manipulation and showing thatba and its complement are part of the same constituent.

The strategy of the extension of senses has further consequences that connections between the canonical resultative, non-canonical resultative and the $b a$-construction can be established.

(55) John da dao Mary si le.

(56) John ba Mary da-si le. (=26)

(57) John da-si-le Mary.

This connection echoes what Fauconnier (1997: p. 137) observes:complex events are integrated into a structure by "making maximum use of existing grammatical constructions". Example (55) contains two separate predicates showing two separate (sub)events. The patient Mary follows $d a$ "hit" and is followed by si "die", predicated of Mary, which in turn reflects the natural sequence of the events (iconicity). Example (56) contains the two predicates merged together but with Mary before the verb $d a$ "hit", and Mary is still understood as the patient. This time, the structure, however, relies on the use of $b a$. Since Mary precedes the two predicates $d a-s i$, the use of $b a$, which manipulates Mary in a particular way, is appropriate.

Without $b a$, the structure of (57) contains only the two predicates that are adjacent to each other making a minimum effort for the action and result, and the structure requires that the patient Mary should follow the two verbs, like an object of them, if they are considered to be a single predicate-this is the only position it can take. The predicates become tighter and closer, but si "die" is still predicated of the patient Mary.

It may be easier to see the influence of $b a$ in the three-dimensional diagram, rather than a two-dimensional one.

(58)

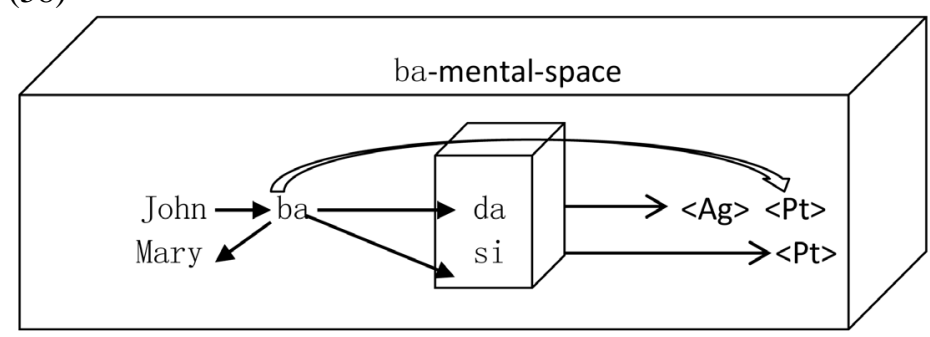

The essential idea behind this is that $b a$ interacts with the lexical semantics of the predicates in the $b a$-complement, in this case, $d a$ and si. While $d a$ projects its own arguments <Agent, Patient> and si its own arguments $<$ Patient $>$, $b a$ facilitates the transmission of force from Agent to Patient, preparing the mental space for Mary to be in a different state. Since there is no Agent for the event si, its Patient argument aligns with the one projected from $d a$-there is only one Patient in the entire $b a$-event. The Patient is also marked by $b a$ as definite or specific - known to the speaker and hearer, as the argument "points to an element $a$ already in some space $M$ " (Fauconnier 1994: p. 20), so that the expression holds in that space.

The mental space interpretation often finds its counterpart as emphasis or focus in the literature. Typologically, creating emphasis and focus of attention requires different structures, and very often non-canonical ones. The example of Johnkicked Mary to death in English specifies the result path to the death of the patient in the canonical clause, while the cleft sentence, which is non-canonical, can put the patient in a focusing perspective It's Mary that John kicked to death. The Chinese ba-construction seems to perform a similar function John ba Mary da-si le in that the patient Mary is focused on and emphasised by $b a$. In other words, the patient Mary is "manipulated" by $b a$ and by the whole construction. In Boas's (2003) terms, $b a$ perspectivises an event in the follow- 
ing complement clause.

This typological interpretation can also have different interpretations within a language. In Chinese the first example below is grammatical but the second one is not.

(59) John ba ma qi-lei-le.

John $\quad b a$ horse ride-tired-asp

John rode the horse and the horse became tired.

(60) *John ba yifu xi-lei-le.

John ba clothes wash-tired-asp

*John washed the clothes and they became tired.

The second example is bad because it is semantically anomalous—clothes cannot feel tired because they are not animate. What is syntactically odd is the use of the ba-construction here. If we understand the structure correctly, we would expect the clothes to be manipulated in a certain way by $b a$, and more particularly, the clothes are manipulated in a way that they are tired. On the other hand, a horse can be manipulated and it can feel tired. This knowledge is our encyclopedic knowledge subsumed in the lexical word.

(61) lei <Experiencer, [+animate] >

This can only be done by considering the $b a$-sentence as a special construction in Chinese, which has its own form, meaning and function. The current proposal does not merely revise Goldberg's (1995: p. 5) claim that "simple clause constructions are directly associated with semantic structures which reflect scenes basic to human experience" but also admits that "scenes basic to human experience" like cause and effect or result are reflected by more integrated constructions, such as tight subordination, and while the cause-and-effect sequences is one of the basic sequences in human experience, its manifestations may take various forms across languages. As Croft (2001: 105) observes, "The universals of language are found in conceptual structure and in the mapping of conceptual function onto grammatical form”.

\section{Conclusion}

The ba-construction in Chinese has been widely studied and most research has focused on the form of the structure and its constraints. This paper has argued that $b a$ is a verb, based upon the concept of Subsective Gradience and behaviour constructions, and its signals subordination, i.e. taking a clausal complement, witnessed by the typological work such as Cristofaro (2003) and Dixon (2010). However, following Huddleston and Pullum et al. (2002), we abandon the traditional distinction between simple sentence and complex sentence, and thus recognise the $b a$-construction as a clausal sentence, which shows strong transitivity in terms of syntactic and semantic parameters-taking a complement clause and manifesting meaning such as impingement or change of state.

The various senses of the $b a$-constructions come from its interaction with the lexical semantics of the verbs in the $b a$-complement. The item $b a$ is considered to be a radial category that projects extended senses in different kinds of discourse. In presenting the discourse, $b a$ acts as a mental space builder perspectivising an event realised by its complement, while focusing on the post- $b a$ argument. This view of $b a$, given its syntax and semantics, is captured by the concept of grammatical blending, mapping the syntax and semantics of the ba-construction. This way of examining a linguistic structure should, I believe, suggest an effective model for analysing structures typologically.

\section{Acknowledgements}

I thank the reviewers for their comments. I also thank the University of Macau for granting me leave during which I completed this paper. I am very grateful to Erasmus Mundus for awarding me a scholarship to visit Freie Universitat Berlin, which supports the research reported here.

\section{References}

Aarts, B. (2007). Syntactic Gradience. Oxford: OUP.

Boas, H. C. (2003). A Contructional Approach to Resultatives. Stanford: CSLI.

Chao, Y.-R. (1968). A Grammar of Spoken Chinese. California: UC Berkeley.

Cristofaro, S. (2003). Subordination. Oxford: OUP.

Croft, W. (1991). Syntactic Categories and Grammatical Relations. Chicago: Chicago University. 
Croft, W. (2012). Verbs. Oxford: OUP.

Culicover, P. W., \& Jackendoff, R. (2005). Simpler Syntax. Oxford: OUP. http://dx.doi.org/10.1093/acprof:oso/9780199271092.001.0001

Ding, P. S. (2007). Studies on Ba Resultative Construction. Lincom: Muenchen.

Dixon, R. M. W. (2010). Basic Linguistic Theory (Vol. 1). Oxford: OUP.

Du, B. (2003). Argument Structure. In W. John, B. Du et al. (Eds.), Preferred Argument Structure. Amsterdam: John Benjamins.

Fauconnier, G. (1994). Mental Spaces. Cambridge: Cambridge University Press. http://dx.doi.org/10.1017/CBO9780511624582

Fauconnier, G. (1997). Mappings in Thought and Language. Cambridge: Cambridge University Press. http://dx.doi.org/10.1017/CBO9781139174220

Frei, H. (1956). The Ergative Construction in Chinese Part II. Gengo Kenkyu, 32, 83-115.

Goldberg, A. E. (1995). Constructions. Chicago: Chicago University.

Goodall, G. (1987). On the Argument Structure and L-Marking with Mandarin Chinese ba. In J. McDonough, \& B. Plunkett (Eds.), Proceedings of NELS 17 (pp. 232-242). Amherst, MA: GSLA.

Grimshaw, J. (1990). Argument Structure. Cambridge, MA: MIT.

Halliday, M. A. K. (2001). On the Foundations of Discourse. In S. Z. Ren et al. (Eds.), Discourse and Grammar. Macau: University of Macau.

Hopper, P., \& Thompson, S. A. (1980). Transitivity in Grammar and Discourse. Language, 56, 251-299.

Huang, C. T. J. et al. (2009). The Syntax of Chinese. Cambridge: Cambridge University Press.

Huddleston, R., Pullum, G. et al. (2002). The Cambridge Grammar of the English Language. Cambridge: Cambridge University Press.

Langacker, R. (1990). Concept, Image and Symbol. Berlin: Mouton de Gruyter.

Li, C., \& Thompson, S. A. (1981). Modern Chinese. Los Angeles, CA: California University.

Li, Y. C. (1974). What Does Disposal Mean? In S. H. Teng (Ed.), Readings in Chinese Transformational Syntax (pp. 93-115). Taipei: Crane.

Liu, Y. H. et al. (1996). Modern Chinese Grammar. Taipei: Taiwan Normal University.

Mangione, L. (1982). The Syntax, Semantics and Pragmatics of Causative, Passive and Ba Constructions in Mandarin. Ph.D. Dissertation, Ithaca, NY: Cornell University.

Mei, K. (1980). Is Modern Chinese Really an SOV Language? In T. C. Tang et al. (Eds.), Papers from the 1979 Asian and Pacific Conference on Linguistics and Language Teaching (pp. 175-197). Taipei: Student Book.

Palmer, F. (1990). Modality and the English Modals (2nd ed.). London: Longman.

Song, Y. Z. (1991). Xiandai Hanyu Yufa Jiben Zhishi (Basic Knowledge of Modern Chinese Grammar). Shanghai: Yuwen Press.

Sybesma, R. (1992). Causatives and Accomplishments: The Case of Chinese BA. Dordrecht: Holland Institute of Linguistics.

Thompson, S. (1973). Transitivity and the BA Construction in Mandarin Chinese. In S. H. Teng (Ed.), Readings in Chinese Transformational Syntax (pp. 75-93). Taipei: Crane.

Tsao, F. F. (1990). Sentence and Clause Structure in Chinese. Taipei: Student Book.

Tsunoda, T. (1994). Transitivity. In R. Asher, \& J. M. P. Simpson (Eds.), The Encyclopedia of Language and Linguistics (pp. 4670-4677). Oxford: Pergamon.

Wang, H. (1984). Baziqu he Beiziqu (Ba-Sentences and Bei-Sentences). Shanghai: Shanghai Education.

Wang, L. (1947/1959). Zhongguo Xiandai Yufa (Chinese Modern Grammar). Shanghai: Chinese Bookshop.

Xu, L. J., \& Liu, D. Q. (2007). Topic in Chinese. Shanghai: Shanghai Education.

Zou, K. (1993). The Syntax of the Chinese BA Construction. Journal of Linguistics, 31, 715-736. 
Scientific Research Publishing (SCIRP) is one of the largest Open Access journal publishers. It is currently publishing more than 200 open access, online, peer-reviewed journals covering a wide range of academic disciplines. SCIRP serves the worldwide academic communities and contributes to the progress and application of science with its publication.

Other selected journals from SCIRP are listed as below. Submit your manuscript to us via either submit@scirp.org or Online Submission Portal.
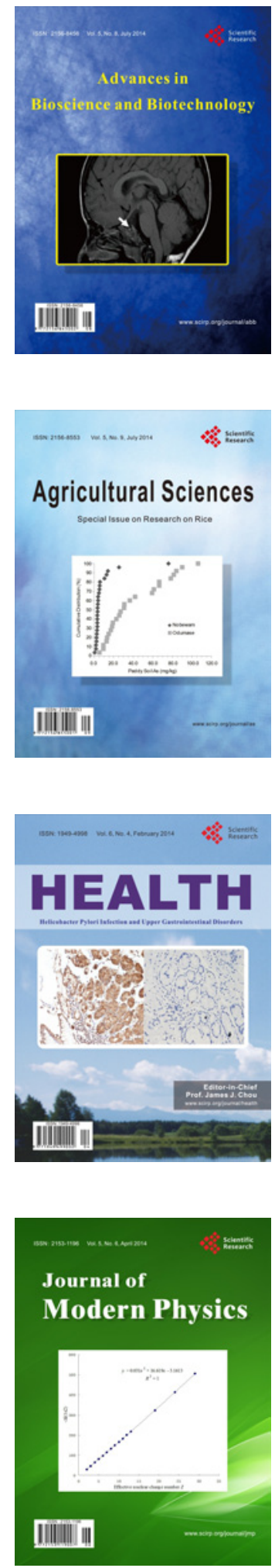
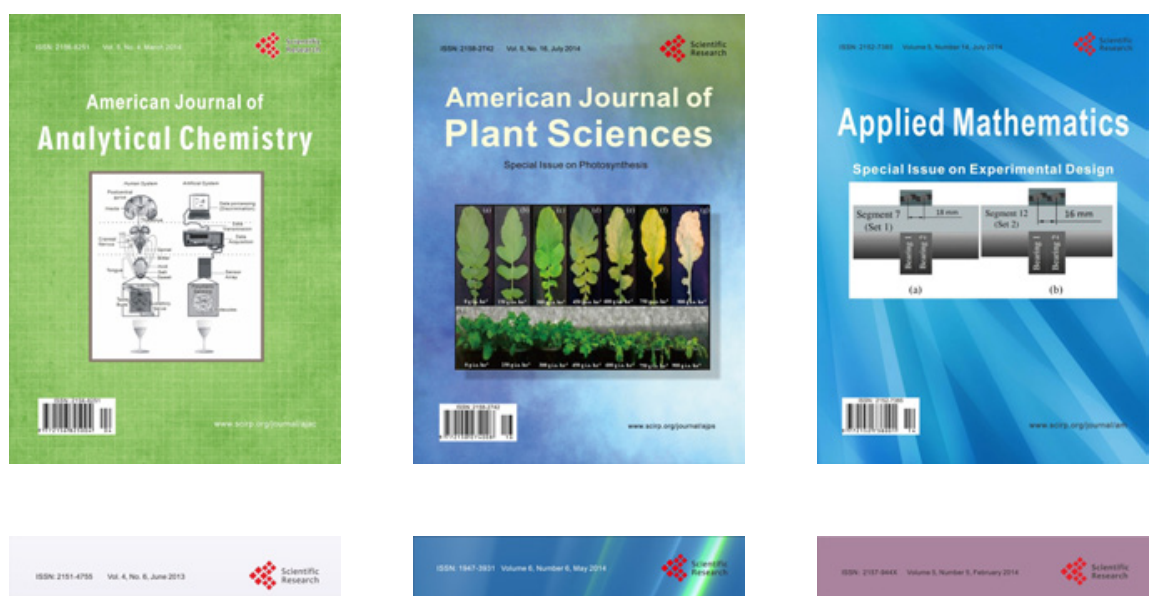

Creative Education
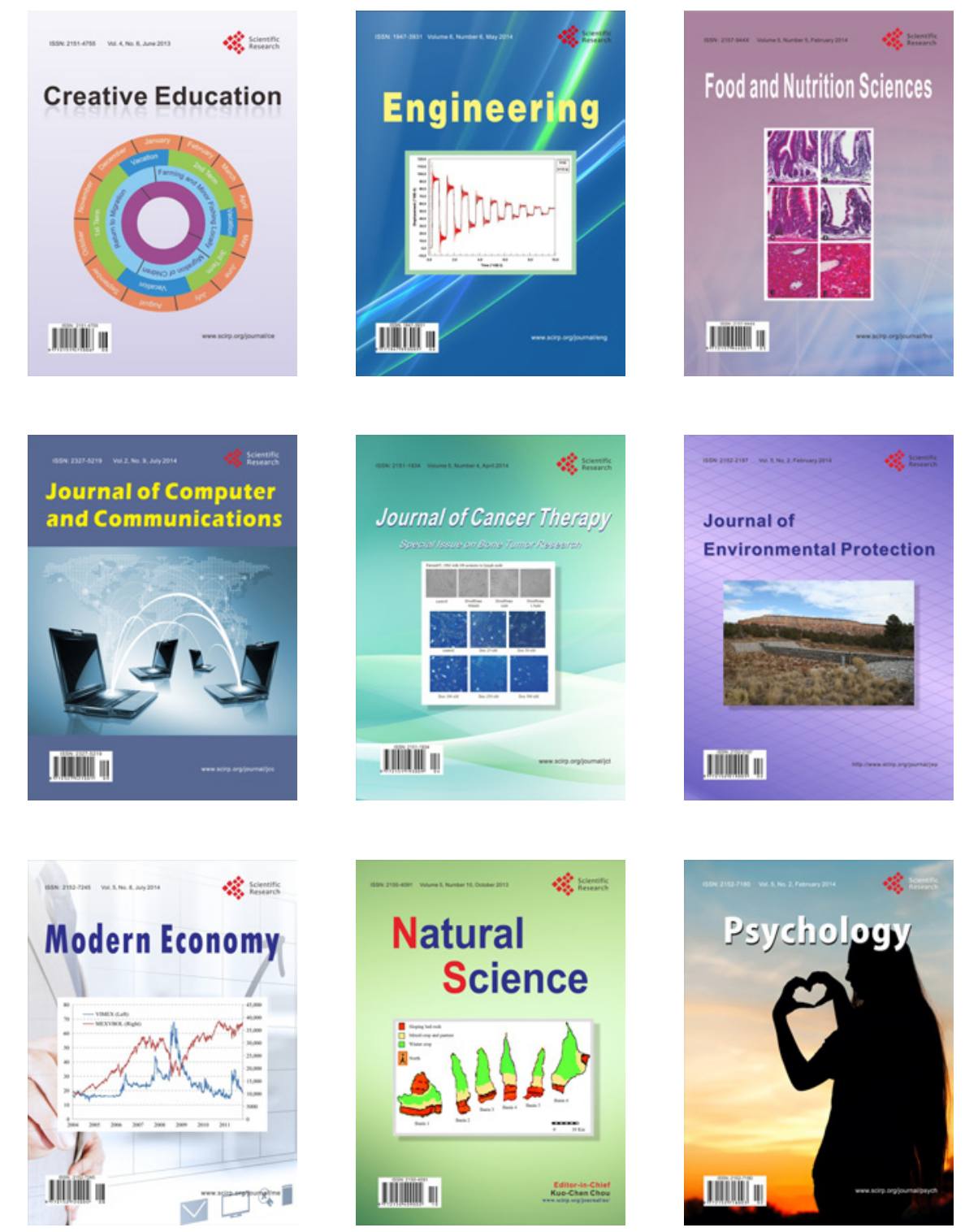